University of Montana

ScholarWorks at University of Montana

Graduate Student Theses, Dissertations, \&

Professional Papers

1974

\title{
A comparison of the test performance of average and below average readers on the McCarthy Scales of Children's Abilities
}

David Alan Johnson

The University of Montana

Follow this and additional works at: https://scholarworks.umt.edu/etd

Let us know how access to this document benefits you.

\section{Recommended Citation}

Johnson, David Alan, "A comparison of the test performance of average and below average readers on the McCarthy Scales of Children's Abilities" (1974). Graduate Student Theses, Dissertations, \& Professional Papers. 7861.

https://scholarworks.umt.edu/etd/7861

This Thesis is brought to you for free and open access by the Graduate School at ScholarWorks at University of Montana. It has been accepted for inclusion in Graduate Student Theses, Dissertations, \& Professional Papers by an authorized administrator of ScholarWorks at University of Montana. For more information, please contact

scholarworks@mso.umt.edu. 


\title{
A COMPARISON OF THE \\ TEST PERFORMANCE OF \\ AVERAGE AND BELOW AVERAGE \\ READERS ON THE MCCARTHY \\ SCALES OF CHILDREN'S ABILITIES
}

\author{
by \\ David Johnson \\ B.S., University of Washington
}

1971

Presented in partial fulfillment of the requirements

for the degree of

Master of Arts

University of Montana

1974

Approved by:
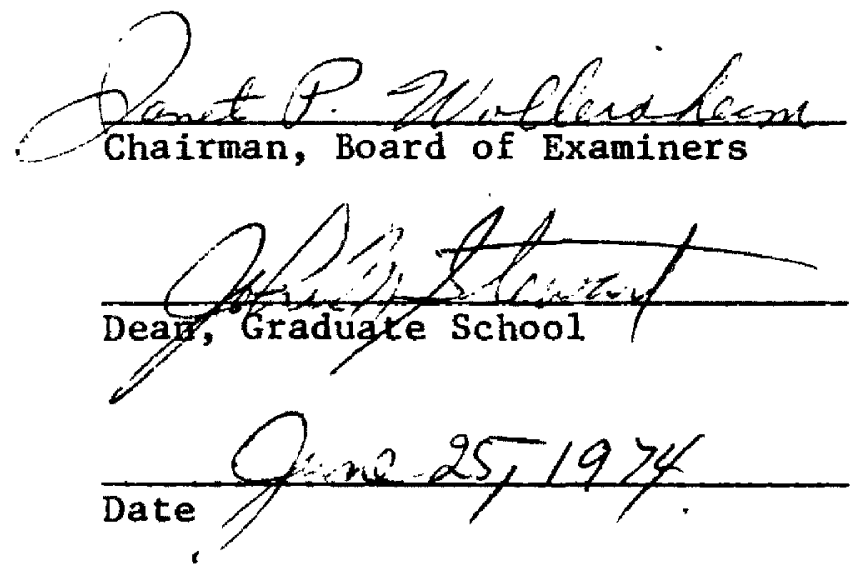
All rights reserved

INFORMATION TO ALL USERS

The quality of this reproduction is dependent upon the quality of the copy submitted.

In the unlikely event that the author did not send a complete manuscript and there are missing pages, these will be noted. Also, if material had to be removed, a note will indicate the deletion.

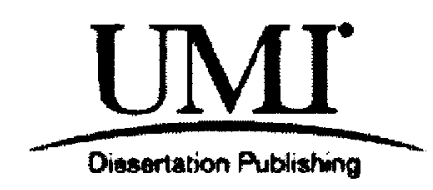

UMI EP38662

Published by ProQuest LLC (2013). Copyright in the Dissertation held by the Author. Microform Edition (C) ProQuest LLC.

All rights reserved. This work is protected against unauthorized copying under Title 17, United States Code

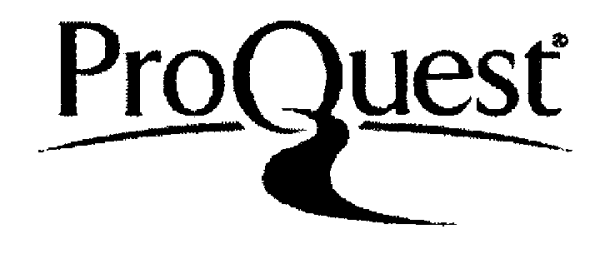

ProQuest LLC.

789 East Eisenhower Parkway

P.O. Box 1346

Ann Arbor, MI $48106-1346$ 
TABLE QF CONTENTS

PAGE

LIST OF TABLES . . . . . . . . . . . . . . . . iii CHAPTER

T. INTRODUCTION ................ 2

Theories of Reading Disability . . . . 3

Factors Associated with Reading Disability 7

Intelligence Test Performance .. . . . 20

The McCarthy Scales ... . . . . . 40

Research Goals ........... . 48

II. METHOD ................ . 51

subjects............. . . 51

Procedure ............. 52

III. RESULTS . . . . . . . . . . . . . 54

IV. DISCUSSION . . . . . . . . . . . 56

v. SUMMARY .................. 65

REFERENCES ..................... 67 


\section{LIST OF TABLES}

TABLE

PAGE

I. WISC Subtest Characteristics of Problem Readers........... . 36

II. Scale and Subtest Organization of the MSCA ............... 43

III. Subject Demographic Data .......... 53

IV. Comparison of MSCA Scale Performance . . . . . 54

V. Group Performance on Five Selected MSCA Subtests........... . 57 
CHAPTER I

INTRODUCTION

One of the major problems confronting the psychologist in an educational or child guidance setting has been the understanding of the phenomenon of the poor reader. For literally decades, a major cause of academic difficulty and failure at the lower grades has been the inability of a child to read. Since the development of effective reading skills serves as a cornerstone for all further academic endeavor, major emphasis has been attached to the elementary school child's reading ability. It is understandable then, that over the years considerable attention has been given to the problem reader, both in terms of understanding the nature of his reading disability and in developing specific remediation techniques. Estimations of the prevalence of reading disability vary considerably according to the criteria used for such a determination (Thompson, 1966). However, it seems that no fewer than $3 \%$ and perhaps as many as $25 \%$ of the U.S. population of elementary school children have acquired reading problems (not reading up to grade level) by the completion of their sixth year (Klasen, 1972). As a result, considerable research and theoretical interest have focused upon the understanding of reading disability. An overview of this research is herein presented. More specifically, a general review of the major theoretical positions concerning reading disability will be delineated, followed by a more detailed description of the numerous factors associated with reading disabiltty. The relationship of these factors to theory and the research pertaining to them are discussed. 


\section{Theories of Reading Disabilities}

Given the vast amount of research attention that reading disability has received, it is not surprising that a substantial number of rather different theoretical positions regarding the nature of reading disability have been advanced. However, most of the comprehensive theories can be grouped into one of three basic categories: (a) those which argue for reading disability as a function of neurological or sensory impairment; (b) those advancing notions of multiple causation of reading disability; and (c) those multiclassification theories which suggest distinctions between types of reading disability.

The first group of theories suggest that the problem of reading disability relates primarily to a single factor: some aspect of impaired or delayed neurological functioning. Orton (1937) and his followers (A. Gillingham, L. Bender) have postulated that reading disability is a distinct neurological peculiarity which Orton referred to as "strephosymbolia" (twisted symbols). This peculiarity was believed to result from mixed or "confused" cerebral dominance where one cerebral hemisphere had not clearly established dominance over the other. Lateral and directional confusion, as well as visual perception anomalles, were cited by Orton as indications that reading disabled children had not developed effective cerebral dominance. Reading difficulties involving letter and word reversals were the result. Kephart (1937), however, argues that the cause of reading disability stems from difficuities in the perceptual process which occurs as a result of faulty or incomplete motor development. For Kephart, the incomplete development of "generalized movement patterns" results in a 
failure to develop laterality, causing the directional confusion which leads to reading reversals. Herman (1959), on the other hand, related reading disability to "word blindness," a hereditary neurological condition Involving localized affliction of the parietal lobe. It, too, was characterized by lateral and directional confusion, as we11 as dyscalculia and dysgraphia (Herman, 1959, p. 17-18). Similarly, Fernald (1943) hypothesized that reading disability is a "brain condition" due to "certain variations in the integrated brain functioning involving higher brain centers," although she believed that the brain condition involved areas associated with visual perception (Fernald, 1943, p. 163-4). A.A. Strauss (1957) suggested that the predominant etiological factor of reading disability involved disturbances in both perception and behavior associated with congenital organic impairment. Adding to Fernald's notions, Strauss argued that "highly discrepant maturation of the psychological functions necessary for integrated auditory and visual perceptual organization cause a significant delay in reading readiness" (Strauss, 1957).

A second group of theories of reading disability, while not denying the relevance of neurological impairment, suggest that social and emotional factors can also serve as primary etiological factors. Helen Robinson (1946) advances such a "multiple-causation" theory, arguing that five basic factors influence reading ability significantly. These factors -- lateral dominance, visual perception, auditory perception, emotional variables and socio-environmental variables -- were all viewed as possible 
etiological factors of reading disability. Robinson believed that any one of them, or any combination of them, could significantly affect the child's reading ability. Similarly, Gates (1947) recognized the importance of "organic defects" as aspects of reading disability, although he believed that they were overemphasized at the expense of the equally important aspects of social and emotional considerations. He suggested that such variables as maturation, educational maturity and teaching techniques could also account for substantial reading problems. Thus, both Robinson and Gates regard reading disability as a multi-factor phenomenon involving a complex array of possible etiological factors occurring either solely or in combinations.

The third group of theoretical positions regarding reading disability have resulted primarily as further elaborations of the multiple causation theories. They have argued for the multiclassification of reading disability "types" based on the frequent observation of the clustering of the various factors in individual cases of reading disability. Essentially, these theories suggest that the phenomenon of reading disability is multidimensional, as certainly more than one type of reading disability can be described. Kolson and Kaluger (1963) argue for a "duoclassification" involving various types and degrees of neurological impairment. "Secondary reading disability," on the other hand, involves an "acquired reading disability having no specific syndrome" and is related primarily to social, emotional and intellectual factors (Kolson and Kaluger, 1963, p. 16-19). In a similar vein, Klasen (1972) delineated three basic "types" of reading disability based on their various etiological variables. "Somatogenic dyslexia" Involves a wide variety of neurological factors including 
functional, constitutional and maturational variables. "Psychogenic dyslexia," on the other hand, involves emotional factors while "sociogenic dyslexia" includes sociological variables. Each is seen as a distinct class of reading disability although Klasen is quick to admit that some "overlap" between these classes frequent1y occurs.

As is readily apparent from the previous discussion of theoretical positions, a substantial number of rather distinct theories regarding the nature of reading disability have been advanced over the years. The basic distinction between these theories, of course, involves their hypotheses concerning the underlying cause (or causes) of reading disability. The first group of theories, those of Orton, Kephart, Herman, Fernald and Strauss, suggest that reading disability can be attributed to a single cause -- neurological impairment. The second group of theories, those of Robinson and Gates, suggest that a number of factors can serve as etiological factors, including social and emotional variables. The third group, including Kolson and Kaluger and Klasen, argue that there are various classes of reading disability, each with its own set of etiological factors. It is of interest to this writer that while such theories differ in their hypotheses concerning etfology, the number and type of characteristics describing the reading disabled child remains fairly constant throughout. Thus, in order to more effectively evaluate the theoretical positions described above, a more detailed examination of those characteristics which seem to distinguish average readers from disabled readers seems essential. Such an examination will be attempted in the next section. 
Factors Associated with Reading Disability

In the literature, it seems that six basic factors have been consistently advanced as significant aspects of reading disability. These six factors -- lateral confusion, visual perception difficulties, auditory perception difficulties, sex differences in the prevalence of reading disability, social-emotional disturbances, and general intellectual deficits -have all been described as major characteristics of reading disability. Since a careful consideration of the relation of these factors to reading disability is necessary for a clear understanding of the problem and related theoretical formulation, a brief review of research involving these areas is presented.

Historically, one of the first and most studied characteristics of reading disability has been laterality. While an unusually large amount of research effort has been directed toward laterality and its relationship to reading disability, it seems as though little has been determined to date. Aspects of lateral confusion such as left-handedness, ambidexterity, mixed eye-hand dominance and directional (left-right) confusion have been described by many (Orton, Kephart, Fernald) as indications of the lack of established cerebral dominance.

The research involving laterality and its relationship to reading disability unfortunately does not provide clear evidence as to its significance. In a review of 14 studies of laterality, Zeman (1967) suggested that "a majority of investigations reveals no significant relationship be- 
tween laterality and dyslexia." Yet Klasen (1972), in a much more extensive review of 30 studies, declared that "the majority of investigators are convinced of at least a positive correlation between lateral confusion and reading problems" (Klasen, 1972, p. 38-46). Interesting1y, some recent evidence has denied the role of mixed cerebral dominance as a significant factor in dyslexia (Cline and Lee, 1972). It has also been noted that mixed eye-hand dominance is not a useful predictor of later reading problems (Clarke, 1971).

Quite obviously, the relationship between lateral confusion and reading disability is still a matter in question. It does seem, however, as Klasen argued, that the majority of studies do establish a positive correlation between the two. Unfortunately, little can be concluded since the nature of the relationship between lateral confusion and mixed cerebral dominance remains to be determined. Thus, the inference of neurological dysfunction from the occurrence of lateral confusion seems highly speculative and certainly premature at this time. Further understanding of neurological functioning is required.

A second major factor frequently associated with reading disability in the literature has been visual perception difficulties. While early studies have established a relationship between visual defects and reading disability (Thompson, 1966, p. 7-31), more recent research has focused on visual perception anomalies such as visual memory, attention span, and visual analysis. Research in this area has, however, been rather fruitless. 
Some studies have noted visual-motor and visual sequential memory abilitles to be significantly associated with reading disability (Tjossem, 1963); (Guthrie and Goldberg, 1972) and to be of predictive value for reading disability for younger children (Bryan, 1964). Others, however, have noted 1ittle or no significant correlation between such factors and reading disability (Golden and Steiner, 1967); (Hartlage, 1970); (Liebert and Sherk, 1970) or in their predictive usefulness (01son and Johnson, 1970).

In general, it seems that little conclusive evidence has been generated with respect to the nature and significance of visual perception difficulties in reading disability. Apparently, both visual defects and visual perception difficulties characterize a substantial number of children with reading problems. Based on the research evidence to date, however, it appears that only a few sound conclusions can be made. It seems likely that among children with recognized visual defects and visual perception difficulties, the incidence of reading disability is substantial. However, among the total population of reading disabled children, the incidence of such visual problems appears to be somewhat less than significant. Thus, while the factor of visual perception seems to be a major component in reading disability, reliance on this factor as a primary etiological variable for the majority of reading disabled children does not seem to be wel1 supported.

Another major factor frequently associated with reading disability has been auditory perception. There seems to be substantial evidence 
which suggests the possibility of central auditory perception difficulties involving auditory discrimination, retention, reproduction and integration as components of reading disability (Klasen, 1972). The major focus of such studies has been placed on the frequent observation of auditory discrimination difficulties with reading disabled children (Larsen, 1971); (Jeffares and Cosens, 1970), indicating pronounced inabilities to effectively discriminate between the vast number of sounds which make up the English language. Cline and Lee (1971) disputed these findings, however, arguing that the major impact of auditory problems seems to lie rather in the area of deficient auditory sequential memory. The analysis of auditory-visual integration abilities seems also to have been a major focus of such research, as investigators have frequently noted the importance of auditory perception in the development of a sight vocabulary (Evans, 1969). Numerous studies (Reil1y, 1971); (Belmont and Birch, 1965) have noted frequent auditory-visual Integration difficulties in reading disabled children.

The literature involving the relationship of auditory perception to reading disability seems much less extensive than the study of visual perception. More recent research indicates that the analysis of auditory difficulties may be more important for the study of reading disability than its visual counterpart (Myklebust, 1964); (Linder and Fillmer, 1970). It seems that more research into this area should be attempted. Significant findings in this area could perhaps shed considerable light on the nature of auditory-perceptual correlates of reading disability.

One of the most intriguing and perhaps least well understood factors 
comnonly associated with reading disability has been simply the sex of the child. Ever since reading disabled children were first systematically studied, investigators have noted the great preponderance of boys within the population of children with reading disorders (Orton, 1937). There is, of course, considerable disparity between studies concerning the ratio of boys to girls within such groups, ranging from 2:1 to nearly $25: 1$ in some studies. Modern educators and researchers, however, seem to accept a nationwide average of about $8: 1$ (Klasen, 1972, p. 23). Thus, reading disability seems to be a more significant problem, numerically, for boys than girls.

There seems to be, basically, two distinct notions behind this phenomenon: those which note the developmental immaturity of boys in comparison to girls in the early grades and those which focus upon environmental influences such as differing educational expectations for boys and the preponderance of female teachers in the primary grades. Considerable documentation from research has been obtained in support of either position and thus the controversy remains. Boys have been found to be infertor to girls in reading speed, vocabulary and comprehension at the primary and elementary levels (Gates, 1961). They have also been found to be deficient in auditory-visual integration abilities and in general reading achievement (Reilly, 1971) suggesting a "generalized maturational lag" for boys in the development of reading skills (Bentzen, 1963). Such results, however, do not seem to preclude environmental arguments. These findings could also be attributed to the boy's perception of the importance of education (Mazurkiewicz, 1960) or to his inability to identify with a female teacher. 
Indeed, Weintraub (1966), in a review of the literature, concluded that while the evidence is, as yet, inconclusive, "convincing evidence for the environmental position outweighs other considerations." However, recent studies seem to more clearly suggest a maturational delay, as sex differences in reading abilities and perceptual skills seem to diminish rapidly with age (Wozencraft, 1967; and Sinks and Powel1, 1965).

Interestingly, intelligence seems to play a major role in these sex differences. It appears that among children of average and below average intellectual ability, girls are clearly superior to boys in reading ability. However, as the intellectual ability of children increases to above average levels, these sex differences disappear (Wozencraft, 1967; Sinks and Powel1, 1965; Weintraub, 1966; and Bentzen, 1963).

Thus there seems to be little controversy concerning the existence of wide sex differences with respect to the incidence of reading disability. Considerable contention, however, seems to exist concerning the relative roles of developmental and environmental influences in this regard. Research also seems to suggest that intelligence plays an important, but not well understood, role in these sex differences. Certainly more research into this matter could provide additional clues as to the significance of sex differences with respect to reading disability.

Another major contributing factor to the phenomenon of reading disability seems to involve the environmental circumstances and emotional characteristics of the reading disabled child. There seems to be an extremely large number of such factors frequently observed to characterize such children. Some of the more major factors seem to include behavioral 
disorders such as hyperactivity and various "nervous habits"; psychopathological reactions such as anxiety, poor concentration; low frustration tolerance and aggression; and environmental circumstances such as low socioeconomic status, cultural expectations, single-parent families and damaging parental attitudes (Klasen, 1972). Social and emotional factors are frequently seen as secondary to primary etiological variables, as they are often considered to be the results of the pressures and anxieties to which a child is subjected when his reading achievement is less than acceptable (Langman, 1960). Other investigators, however, suggest that these variables can serve as primary etiological factors for reading disability (Thompson, 1966). Chandler (1966) has determined, in an extensive review of the literature, that the environmental influence of low socioeconomic status serves as a significant component of reading disability. Interestingly, however, numerous studies, while accepting Chandler's conclusions, have noted that the significance of socioeconomic status as a factor or reading disability diminishes if the IQ level of the child is within or above the normal range of functioning (Reid and Schoer, 1966).

With respect to the emotional correlates of reading disability, Thompson (1966), in an interesting review of the psychoanalytic literature, concluded that three basic factors seem to be associated with reading problems: fear and avoidance of looking, hostility (primarily toward the same-sex parent) and failure to identify with the same-sex parent. Walters, Van Loon and Crofts (1961) however, suggested that, as a result of their research, these problems do not effectively distinguish disabled readers from other children. 
The research and speculation into the relationship of social and emotional factors and reading disability is extremely extensive and broad in scope. Thus, a detailed review of the area is beyond the range of the present discussion. It should, however, be sufficient for our purposes to realize that such variables cannot be disregarded in the study of reading disability. They certainly contribute to reading problems and perhaps even serve, for some, as primary etiological variables. The exact nature of such factors, and the extent of their influence on reading disability is, of course, as yet to be determined.

The sixth and final component of reading disability which has received considerable attention has been the study of the relationship between intelligence and reading disability. The question is still raised repeatedly whether specific reading disability occurs in association with mental retardation and whether it should be considered as a partial defect of intelligence. While it seems that lower level mental functioning frequently precludes effective grade-level reading development (Fildes, 1921), the research seems to clearly indicate that reading disability can, and does, occur at a11 intellectual levels. As Klasen (1972) argued:

It appears that more and more investigations lead to the conclusion that dyslexia is independent of the intelligence factor and that it is evenly distributed among all degrees of intelligence. (p. 108).

Thus, it is not surprising that conflicting data frequently appear in the literature with respect to intelligence and reading disability. It seems that simple differences in samples can lead to quite different 
intellectual characteristics between groups. Thus, some studies suggested only a slight and insignificant relationship between intelligence and reading disability (Sinks and Powell, 1965) and little usefulness of estimates of intellectual functioning in the prediction of reading disability (Tjossem, Hanson and Ripley, 1962). Others, however, found a significant relationship (Bentzen, 1963); (Neville, 1965) and effective predictive utility (Bryan, 1964) of measures of intelligence.

Since there seems to be little contention with the frequently observed problem of reading disability with retarded children, most recent studies have controlled for the influence of intellectual factors by limiting their studies of reading disability to subjects of normal intelligence. As a result, a vast amount of research has been attempted with respect to the careful analysis of patterns of intellectual deficits as measured by intelligence tests. To date there has been extensive interest in the subtest performance of reading disabled children on various measures of intelligence (primarily the Wechsler Intelligence Scale for Children (WISC) ), and many rather interesting conclusions have resulted. It is this aspect of the research to which the present research effort will address itse1f.

Prior to a review of the research involving the analysis of intelligence test results for reading disabled children, a few summary remarks should be made concerning the factors associated with reading disability. In general, there seems to be six major areas of research interest with respect to the discussion of factors involved in reading disability -laterality, visual perception, auditory perception, sex differences, socio- 
emotional variables and intelligence. It seems safe at this point to suggest that each can be shown to significantly correlate in one way or another with reading disability. However, the precise understanding of the role of each factor and its overall importance with respect to reading disabilities has not, as yet, been clearly established. Thus what remains is a considerable amount of often intricate intercorrelations between these factors and between each factor and the phenomenon of reading disability. The result is, unfortunately, a confusing and often misleading plcture of the nature of reading disability. Speaking directly to this problem, A.N. Applebee (1971) indicated that:

Research in reading retardation has a long history of conflicting results and opposing theoretical orientations. The conceptual framework of disciplines ranging from education to medicine have been used in numerous attempts to explain and treat the problems of students who have repeatedly failed to learn basic reading skills. Such a diversity has been healthy, illuminating many different facets of the disorder, yet in spite of the intermittent efforts of many and the dedicated and continuing efforts of a few, there has been no real success in what, for the school child at least, must be the most important goals of such research: namely, (1) to predict reliably in advance which students will have difficulty in learning to read, (2) to relate specific cases of the disability to a particular cause, or (3) to develop remedial measures geared to the individual student.

Perhaps at the root of these relatively unsuccessful results of the research as pointed out by Applebee are two basic problems with the research in reading disability. First there is the obvious problem of the lack of an accurate definition of reading disability. Secondly, since nearly all of the studies are correlational in nature, little interpretive 
signiflcance relating to etiology can be confidently established.

Certainly, the problem of definition is a crucial one of tremendous significance in research relating to reading problems. Not only are there wide variations in the conceptual definitions of reading disability, depending on one's theoretical biases, but, more importantly, there are numerous differences in the operational definitions used in the research articles themselves. First of all, a wide array of reading achievement and general achievement tests are used in the literature. As a result, it is quite possible that substantially different aspects of reading disability are being measured.

Secondly, it is also evident that wide variations in the degree of reading retardation are also found in the operational definitions. The result is, of course, that the research results of one study are not always directly comparable to those of other studies. Thus, different conclusions are reached causing considerable controversy which may be merely expressions of the differing degrees of reading retardation employed.

Thirdly, there are also major differences between studies with respect to the standard used for assessing reading achievement. While most studies use the expected grade level reading achievement as a basis for determining reading disability, some continue to use estimations of expected reading achievement levels based on the child's IQ or mental age. The use of such IQ estimations for expected reading achievement is neither valid nor fair to the child. This is due to the fact that the teaching of reading skills in the public schools is not usually tailored to the child's Intellectual capacity but to his grade level in school. Thus, in some 
studies, the child's reading ability is assessed according measures of intellectual capacity regardless of the restrictions of grade-level reading instruction. Quite obvious1y, the likelihood of defining certain children of above-average intellectual capacity as reading disabled is greatly increased. Of course, this problem substantially confounds the issue of reading disability.

A second basic problem in the literature involves the predominant use of statistical procedures which are most often correlational in nature, yielding resuits which only point out relationships between a factor or set of factors and reading disability. This is not to suggest that such correlational research is neither valid nor useful. Frequently, a determination of the inter-relationship between variables is both enlightening to the research person and useful to the clinician. However, the use of correlational procedures limits the types of statements which can be advanced concerning the factors involved, as the specific natures of their relationship cannot be determined. Thus, only speculative hypotheses rather than cause-effect statements concerning the nature of the relationships can be attempted.

The ramifications of these research problems are perhaps obvious. The lack of an established operational definition of reading disability has led to the mistaken assumption that reading disability is a unitary phenomenon not subject to substantial individual differences. If one is to believe the literature, then certainly this is not the case. The phenomenon of reading disability may be quite different for different age groups, different sexes and different overall intellectual levels. 
Perhaps more important1y, research which investigates factors commonly associated with reading disability is necessarily correlational in nature. While such research allows for the association of numerous factors with reading disability, it does not allow for a determination of etiological significance. The unfortunate result is that we must rely on speculative hypotheses concerning the nature of reading disabilfty without having realistic procedures to verify them.

Given these research problems, one must recognize the speculative nature of research findings and of theoretical formulations. However, the 30 (or so) years of investigation have given us some important information concerning the nature of reading disability. The "neurological" theories of Orton, Kephart, Fernald and others have, it seems, provided convincing arguments for the possible significance of neurological dysfunction in reading disability. The research involving lateral confusion, and visual and auditory perceptual difficulties certainly can be interpreted as a substantiation of their notions. However, the interesting research involving social and emotional variables seems to reveal that such factors can also be of crucial significance in reading disability, as Robinson (1946) and Gates (1947) have pointed out.

The results of research, as far as this author is concerned, seem to strongly support the multiclassification theories, such as those advanced by Kolson and Kaluger (1963) and Klasen (1972). It appears evident that reading retardation is not a unitary phenomenon, as implied by Orton and others. Rather, it seems that reading ability can be significantly influenced by a wide range of factors and combinations of factors. 
Perhaps it is this determination -- different classes of reading disability -m that can account for the ambiguous and somewhat confuging research findings. Thus it seems that future research should focus on the identification of these different classes, and on the relevant factors which may distinguish them.

\section{Intelligence Test Performance}

A common research approach in the analysis of intelligence test performance of reading disabled children has been to determine whether a pattern of specific test results could be found to characterize the group. Since the organization of the Wechsler Intelligence Scale for Children (WISC) seemed to most easily lend itself to such an analysis, it has been nearly exclusively used as the instrument of choice. This has obviously led to a more detailed analysis of the samples of intelligence measured by the WISC. It has a1so, however, allowed for the easiest comparison of the various research attempts and their results, a phenomenon non-existent with respect to the literature previously mentioned.

The first major research effort in this area was a study by Graham (1952) in which 96 children of ages $8-0$ to $16-11$, were administered the WISC. Subjects were selected on the basis of their being referred to a clinic for reading problems. Of this group the test results of 31 children who scored greated than 90 on either the Verbal Intelligence Quotient (VIQ) or the Performance Intelligence Quotient (PIQ) of the WISC, and who were also found to be underachieving in reading as measured by 
the Wide Range Achievement Test (WRAT), were analyzed to determine if there was a pattern of subtest performance on the WISC. Graham found that these children tended to score lower than the standardized mean (10) on the Information, Arithmetic, Digit Span, Vocabulary and Coding subtests. He failed to report the statistical significance of these results however, and thus, little interpretation of his results is possible.

In 1955, Burks and Bruce attempted to study the characteristics of good and poor readers' performance on the WISC. They used 42 third through eighth grade children, all with Full Scale Intelligence Quotient (FSIQ) scores of greater than 90. The authors then divided them into a "good readers group" of 1 I children (6 female, 5 male) characterized by reading achievement scores of at least one grade level above expectancy as measured by the WRAT, and a "poor readers group" of 31 children (5 female, 26 male) whose reading achievement was at least one year below grade level expectancy. A subtest analysis of their WISC performance was attempted. It was found that the poor readers received higher scores in comparison to the good readers on the Comprehension, Block Design, and Picture Arrangement subtests and lower scores on the Information, Arithmetic and Coding subtests. However, since there was a 16-point FSIQ difference between the two groups in favor of the good readers, some doubt is cast on the validity of these findings, as IQ level has already been shown to be an important factor in reading disability.

In one of the most frequently cited research efforts, Altus (1956) studies 25 "retarded readers" (24 male, 1 female) to determine a profile of subtest results on the WISC. The subjects were third through eighth 
retarded readers, evaluating the WISC performance of 34,8 to 14-yearold children (29 male, 5 female) referred to a clinic for reading problems. Each child was determined to be at least two years retarded in reading achievement on the basis of the discrepancy between expected reading leve1 as defined by the FSIQ of the WISC and the actual reading level as determined by Gray's Oral Reading Test. Dockrell found that these children scored significantly below the established test norms on the Information, Arithmetic and Coding subtests. They were also found to score significantly above the test norms on the Comprehension, Similarities and Picture Arrangement subtests. While these test results tend to agree in general with those previously cited, they must be viewed with some caution as the definition of reading retardation used in this study (based on expected reading level derived from IQ scores) is somewhat questionable for reasons which will be discussed at a later point.

In a study very similar to the previous one, Robeck (1960) attempted to evaluate the subtest patterning of problem readers on the WISC. The author administered the WISC to each of 37 seven to thirteen-year-old children enrolled in a reading clinic and evaluated the deviation of each subtest score from the child's overall subtest mean score. While Robeck's results are generally comparable to those of Dockrell, there are some differences which warrant further comment. Robeck not only found these children's performance to be weakest on the Arithmetic, Coding and Information subtests, she also noted significant strengths on the Comprehension, Similarities, Vocabulary, Picture Completion, Picture Arrangement and Block Design subtests. There seem to be two 
major distinctions between the studies of Robeck and Dockrell which could account for the difference in results: First, Robeck did not operationally define "problem readers" as did Dockrell. She indicated rather that while all of her subjects had reading problems of sufficient severity to warrant their enrollment in a reading clinic, there was a wide range of reading disabilities. Secondly, there was a wide range of IQ levels within her group ( 85 - 136) which may have altered her results somewhat, perhaps accounting for the noticeable differences between studies. In a slightly different analysis of the WISC subtest scores of problem readers, Hirst (1960) attempted a two-way analysis of the "subtest scatter" of the WISC. First, he compared remedial readers' performance with respect to the standardized mean scores of subtests. Secondly, he attempted an intra-individual comparison of relative strengths and weaknesses of each child. Test results of 30 children of ages $8-0$ to 13 - 6 enrolled in a remedial reading program were analysed. Each was reading at a level of at least six months below mental age expectancy as defined by the Chicago Silent Reading Test. Hirst then divided the group into severe and mild reading disability groups. He found that, in general, the total group (both reading disability groups combined) was low on the Digit Span, Arithmet1c, Coding and Vocabulary subtest and was high on the Picture Completion and Picture Arrangement subtests. While there were a number of differences between the two groups, the major distinction was that while only $5 \%$ of the mild group was high on the Object Assembly subtest, fully $42 \%$ of the severe group showed significantly higher results on this subtest. Interestingly, Hirst's two-way analygis described pre- 
viously, yielded essentially the same results, indicating a basic similarity between group and intra-individual strengths and weaknesses with respect to their subtest performance.

Neville (1961), attempting a comparison of the WISC subtest patterns of male retarded and non-retarded readers, studied the test performance of 53 "retarded readers" referred to a clinic for evaluation. He compared their results to those of 35 "non-retarded readers" who were also referred to this clinic, but were found to be reading at acceptable levels. The retarded readers were defined as those scoring at least two years below grade level on the Florida Reading Scales. The two groups were closely matched for IQ, grade level, and sex (all male) and all had FSIQ scores of greater than 90. The author found the "retarded readers" to score significantly lower than the "non-retarded readers" on the Information, Arithmetic and Digit Span subtests $(\mathrm{p}<.01)$ and significantly higher on the Picture Arrangement and Block Design subtests. He commented that this pattern of results tends to indicate low scores on schoolrelated tasks and higher scores on the non-formal learning tasks. The generalization of his findings seems somewhat spurious however, as his non-retarded readers, all of whom were referred to a clinic for evaluation, probably cannot be considered as a strictly random sample of the population of children with average reading abilities.

In a welcomed addition to the design of such research, Kallos, Grabow and Guarino (1961) carefully controlled for IQ range, suspecting that the subtest pattern for retarded readers might vary according to the intellectual level of the subjects. They analysed the WISC subtest 
patterns of 37 boys of ages 9 through 14 , restricting the range of IQ to the 90 - 109 range as determined by the FSIQ. A11 the subjects were at least two years below expected grade level reading achievement as measured by the Durrell Analysis of Reading Disability test. Their results were quite consistent with previous research. They noted significantly lower performances on the Information, Arithmetic, and Coding subtests and significantly high scores on the Block Deslgn subtest in comparison to the standardized mean. These results led the authors to suggest that deficient visual-motor abilities play a primary role in reading disability, although one wonders if the high Block Design scores are consistent with this notion.

Paterra, in a 1963 study of WISC "scattergrams" of retarded readers, analyzed the WISC performance of 33 school children of average to very superior intelifgence who were referred for evaluation of reading problems. Their scores were analyzed according to the deviation of each subtest score from the individual child's overall mean of subtest scores. These children, from grades $1-9$ (age $6-5$ to $14-6$ ) were found to score high on the Comprehension, Similarities and Picture Completion subtests while scoring low on the Arithmetic and Vocabulary subtests. Paterra also found some interesting results with respect to VIQ and PIQ scores which will be discussed at a later point.

In an extremely interesting and well-designed study, McLean (1963) attempted a comparison of two groups of retarded and non-retarded readers (emotionally disturbed and well-adjusted). He hoped to establish whether two groups of retarded readers (well-adjusted and emotionally disturbed) 
gave differential performances on the WISC when compared to like groups of non-retarded readers. The groups were closely matched according to sex, age, race, IQ, educational background, urban-rural residence and socioeconomic status. A criterion of two years below grade level in reading achievement as defined by the Stanford Achievement Test was used. McLean then studied the WISC results of the 84 , fourth to sixth grade boys. Emotional disturbance was evaluated by school personnel on the basis of the child's use of "undesirable, deviant behaviors felt to be indicative of emotional problems by the school personnel." McLean's results provided a wealth of extensive information concerning the influence of emotional disturbance on test performance. However, his results in general indicate low scores of retarded readers in comparison to average readers on the Information, Arithmetic, Vocabulary, Digit Span and Coding subtests and high scores on the Picture Completion subtest irrespective of the presence of emotional disturbance. The presence of emotional factors in reading retardation seems to be associated with elevated scores on those subtests on which the child tends to score high and with depressed scores on those subtests on which the child tends to score low. Interestingly, the WISC profile of the emotionally disturbed, non-retarded readers was quite similar to the profiles of both retarded reading groups. This would suggest that the factor of emotional disturbance has a similar effect on the WISC test performance of children as reading retardation, and that the two effects are additive. While it is possible to raise a number of serious questions concerning the adequacy of the "rating" of emotional disturbance, McLean's study represents a major advance in the careful design of research 
studies in this area.

In a follow-up of her previous study, Robeck (1964) reported on the WISC subtest scores of 80 children (68 males, 12 females) enrolled in a reading clinic whose ages ranged from $10-6$ to $13-9$ and whose IQ's ranged from 72 - 136 . Her results indicated the individual intellectual strengths and weaknesses of these children. Robeck noted strengths on the Comprehension, Similarities, Vocabulary, Picture Completion and Block Design subtests. As in her earlier study, Robeck noted performance deficiencies of the retarded readers on the Information, Arithmetic, Digit Span and Coding subtests. These results supported her earlier findings (Robeck, 1960) although they suffer from the same methodological problems of her previous research. These include the lack of an operational definition for reading retardation and the failure to control adequately for IQ level. She suggested, however, that these results indicate that reading disabled children tend to score high on tests of judgment and abstraction while scoring lower on tests involving the ability to recall specific verbal material. This seems to be in general agreement with the previously discussed conclusions of Neville (1961).

McLeod (1965) attempted a comparison of the WISC subtest scores of pre-adolescent successful and unsuccessful readers. He used 116 children referred to a clinic for reading disability and 177 "successful" readers who showed no reading problems in their school performance. All of the children were above the age of $10-6(\bar{x}=12.4)$ and had FSIQ scores of between 80 and 120 . The "unsuccessful" readers were at least one and a half years retarded in their reading achievement relative to their chrono- 
logical age. McLeod's results indicated significantly lower scores for the "unsuccessful" readers on the Information, Vocabulary, Digit Span and Coding subtests and significantly higher scores on the Picture Completion subtest, in general agreement with previous research.

In a much more extensive and interesting research effort, Sawyer (1965) advanced the study of WISC profile of retarded readers by studying two distinct groups of retarded: severe and mild. While both groups of readers were defined to be those who scored at least one year behind expected reading achievement level (the specific test measure was not reported), and two groups were distinguished by their progress in reading achievement. The mildly retarded readers group had all made at least half of their expected progress in reading while the severely retarded readers had not. Using 90 children of three age categorles $(8-0,10-5$, 13 - 0) in each group, all FSIQ's between 91 and 119, Sawyer's results suggested that a discrimination between the mildly and severely retarded reading groups was possible through the use of "weights" applied as multipliers to the subtest raw scores. She also found that the WISC could be used as an effective predictor between mild and severe reading disability groups at the younger age levels, with the Information, Arithmetic and Vocabulary subtest being the most effective. The Digit Span, Picture Completion and Block Design subtests were the least effective predictors. An important aspect of Sawyer's research to note is that this research represents the first major attempt to delineate the pattern of WISC subtest results between "classes" of retarded readers. While her results were not overwhelmingly successful, they do seem to lend some support for 
the notion of different "types" of reading disability; a notion too infrequently considered in the literature.

Ekwall (1966), in a study of the usefulness of WISC subtest profiles in the analysis of reading difficulties, studied the test results of 40 fourth and sixth grade children. Each child had a FSIQ score above 85, and was at least two years retarded in reading achievement with respect to grade level according to Gray's Oral Reading Test. Twenty-one of his subjects were bilingual, although the possible significance of this variable was apparently not considered. His results showed primarily the same results as those of previous studies, with low group scores on the Information, Arithmetic and Digit Span subtests and high group scores on the Picture Completion and Picture Arrangement subtests. However, he also noted low scores on the Comprehension subtest and high scores on the Object Assembly and Coding subtests, unlike previous research findings. Since he did not report the average IQ level of his subjects and did not have a control group, these are somewhat ambiguous results and must be viewed with caution.

In one of the few studies controliing for the possible effects of socioeconomic status (SES) on reading achievement and WISC test performance, Reid and Schoer (1967) studied the WISC subtest patterns of 87 fourth-grade males. They attempted to determine the relationship between these subtest patterns and reading achievement and SES. IQ's for all the subjects were between 90 and 109 while reading achievement was defined through the use of the Iowa Tests of Basic Skills. Those students scoring In the upper quartile of the test were designated as "above average 
readers" while those scoring within one half year of grade placement were termed "average readers." Those scoring in the lowest quartile were described as "below-average readers." All subjects were also assigned to a low, middle or upper SES group on the basis of the education and occupation of the head of the household. Their results indicated lower scores for the below-average readers in comparison to the other groups on the Arithmetic, Similarities and Digit Span subtests and higher scores on the Picture Completion subtest. Interestingly, the authors found no effect of SES level for any reading group with respect to subtest scores. This allowed them to speculate that the well-known effects of SES (especially lower SES) on WISC subtest performance tend to disappear when the overall IQ level of the child is restricted to the normal range.

In an extensive study of the intellectual profile of retarded readers on the WISC, Belmont and Birch (1966) analysed the WISC scores of a group of 150 disabled readers, 9-year-old males, and a similar group of 150 9-year-old average male readers. Reading ability was defined by their relative performances on the British Sentence Reading Test and the Metropoliton Achievement Test. The retarded readers were defined as those who scored at or below the tenth percentile on the tests. A11 subjects were equated as nearly as possible for IQ level and SES. Their results indicated significantly lower scores for retarded readers on the Information, Arithmetic, Vocabulary, Object Assembly and Coding subtests, leading them to conclude that the inadequacy of language functioning rather than perceptual or motor functioning characterized thetr reading disabled group. Corwin (1967), assessing the relationship between reading achievement 
and intelligence test performance, studied the WISC subtest patterns of 30 good and 30 poor fourth and fifth grade readers. The groups were matched for age, grade and Lorge-Thorndike Non-verbal IQ. Reading achievement was determined solely on the basis of teacher evaluation. His results were basically consistent with previous research, as he found significantly lower scores for poor readers in comparison to the good readers on the Information, Arithmetic, Digit Span and Coding subtests. The initial selection of subjects on the basis of non-verbal IQ test results may have influenced the findings however, as it is possible that such a procedure eliminated performance test differences between the two groups and accentuated the verbal test differences. Also, the use of teacher evaluation of reading retardation may identify a group of problem readers dissimilar to those identified as problem readers by objective tests.

An interesting study by DeBruler (1968) was perhaps the first to systematically note the sex differences on the pattern of subtest scores for retarded readers in their performance on the WISC. Two groups of 70 seventh grade children were matched for age, IQ, school grade, SES and educational background but differed in reading ability as measured by a reading achievement test (unspecified). The author noted significantly lower scores on the Arithmetic, Vocabulary and Coding subtests and higher scores on the Picture Completion subtest for the retarded readers. DeBruler also noted some interesting sex differences, as the Information, Arithmetic and Vocabulary subtests seemed to differentiate between female retarded and non-retarded readers (lower scores for the female 
retarded readers) while lower Arithmetic and Coding scores and a higher Picture Completion score for the male retarded readers tended to differentiate between the male reading groups. Thus, the Artthmetic subtest was found to be the only subtest on which both sexes of retarded readers scored lower than the non-retarded readers. The Verbal Scale tests of Information and Vocabulary most successfully distinguished the female reading groups while the Performance Scale subtests of Picture Completion and Coding most effectively distinguished the two male reading groups. DeBruler's effort represented the first major study which attempted to analyse sex differences in subtest performance. Interestingly, his results indicated some rather intriguing differences, suggesting that the factor of sex must be taken into account in these studies.

Lyle and Goyen (1969) studied 54 retarded and 54 non-retarded readers in order to determine if there is a pattern of subtest results on the WISC for such children. They also hoped to determine if reading retardation is an isolated problem or if it is simply one aspect of general educational underachievement. Using first through sixth grade subjects, the authors administered Schonell's Graded Word Reading Test to identify poor readers. They defined this group operationally on the basis of a sliding scale of degree of discrepancy between reading achievement and grade level from first grade (six month retarded) to sixth grade (two-and-a-half years retarded). The authors subsequently studied the subtest performance of each child on the WISC and found a pattern of low scores for poor readers on the Information, Arithmetic and coding Subtests for all retarded reading groups regardless of age. This finding is somewhat contrary to previous 
research which has indicated basic changes in the nature of subtest performance with respect to age levels, although Lyle and Goyen's results may be the function of the use of their sliding scale of reading retardation. Previous studies have used only one criterion (usually two years) for all ages of subjects with respect to the degree of reading retardation. Further research investigation of this matter should be attempted so that a more precise determination of the effects of increasing age on the subtest performance of retarded readers could be more accurately assessed. Finally, a more recent study by Huelsman (1970) attempted to analyse the WISC subtest "syndrome" of retarded readers and their application for diagnostic purposes in the Individual case. One hundred fifty-seven over and underachieving fourth grade readers were selected according to their performance on the Gates Reading Survey tests. The author found that lower Information, Arithmetic and Coding subtest scores tended to characterize his group of retarded readers. Interestingly however, few of the individual subtest scores were significantly lower on any of the subtests in comparison to the performance of over-achieving readers. This would suggest that such subtest results are perhaps a characteristic of statistical procedures involving group comparisons and are not generally applicable to the individual case.

In general, it seems as though a fairly consistent pattern of subtest results for reading disabled children on the WISC has been determined in the literature. Of the 21 studies reviewed here, 14 have noted low scores on the Information subtest; 18 found low scores on the Arithmetic subtest; 11 have reported low scores on the Digit Span subtest. 
Sixteen studies have noted low Coding subtest scores, while 10 have reported high scores on the Picture Completion subtest.

A comprehensive summary of these results in table form, is presented in Table I. Patterns of performance of below average readers for each study previously reviewed are recorded in Table I, as are the percentages of studies reporting significantly lower or higher scores for each subtest.

Thus, for the WISc, it appears that the Information, Arithmetic, Digit Span, Picture Completion and Coding Subtests tend to most effectively discriminate between groups of retarded and non-retarded readers. Utilizing Cohen's analysis of the factorial structure of the wISC at ages $7-6,10-6$, and $13-6$ (Cohen, 1959), some interesting notions concerning the possible meaning of these subtest differences can be advanced. Cohen notes that the Information and Arithmetic subtests load primarily on his Factor A: Verbal Comprehension I for all age groups. This would indicate that retarded readers have a deficiency in the aspect of verbally retained knowledge impressed by formal education. The Digit Span subtest, however, loads primarily on his Factor C: Freedom from Distractibility for all ages, perhaps indicating an attentional difficulty for reading disabled children. The coding subtest loads mainly on Cohen's Factor E: an un-named, un-described factor which, if understood, could perhaps shed important light on the problem, since Coding seems to be such an effective discriminator between reading groups. Picture Completion, the only subtest on which the retarded readers tend to score consistently higher than normal readers, loads heavily on Factor D: Verbal Comprehension II for all ages. This tends to Indicate a facilfty for retarded 
WISC Subtest Characteristics of Problem Readers

WISC Subtests

\begin{tabular}{|c|c|c|c|c|c|c|c|c|c|c|c|c|}
\hline Date & Author & $I$ & C & A & $s$ & $\mathrm{v}$ & DS & PC & $\mathbf{P A}$ & $\mathrm{BD}$ & OA & Co \\
\hline 1952 & Graham & L & & $\mathrm{L}$ & & L & L & & & & & L \\
\hline 1955 & Burks & L & H & L & & & & & H & В & & $\mathbf{L}$ \\
\hline 1956 & Altus & L & & L & & & & H & & & & L \\
\hline 1959 & Sheldon & & & L & & & & & & & & $\mathbf{L}$ \\
\hline 1960 & Dockrell & L & н & L & H & & & & $\mathbf{H}$ & & & L \\
\hline 1960 & Robeck & L & H & L & H & H & $L$ & $\mathrm{H}$ & H & $\mathrm{H}$ & & L \\
\hline 1960 & Hirst & & & I & & L & L & H & H & & & L \\
\hline 1961 & Neville & L & & L & & & L & & H & H & & \\
\hline 1961 & Ka11os & L & & L & & & & & & $\mathbf{H}$ & & L \\
\hline 1963 & Paterra & & H & L & $\mathrm{H}$ & L & & $\mathbf{H}$ & & & & \\
\hline 1963 & McLean & L & & L & & L & L & H & & & & L \\
\hline 1964 & Robeck & $\mathbf{L}$ & H & L & H & H & L & H & & H & & L \\
\hline 1964 & Sanstedt & & & & & & L & & & & & \\
\hline 1965 & McLeod & L & & & & $\mathrm{L}$ & L & H & & & & L \\
\hline 1966 & Belmont & $\mathbf{L}$ & & L & & L & & & & & L & L \\
\hline 1966 & Reid & & & L & I & & L & H & & & & \\
\hline 1967 & Corwin & L & & L & & & L & & & & & L \\
\hline 1968 & DeBruler & & & $L$ & & L & & H & & & & L \\
\hline 1968 & Ekwa11 & L & L & $L$ & & & L & $\mathbf{H}$ & $\mathbf{H}$ & & H & $\mathrm{H}$ \\
\hline 1969 & Lyle & L & & L & & $\mathbf{L}$ & $\mathbf{L}$ & & & & & L \\
\hline 1970 & Huelsman & L & & L & & & & & & & & L \\
\hline 1972 & Klasen & & $\mathrm{H}$ & L & & & L & & & & & $L$ \\
\hline
\end{tabular}

\begin{tabular}{|l|c|c|c|c|c|c|c|c|c|c|c|}
\hline Percentage low & 68 & 4.5 & 91 & 4.5 & 45 & 59 & 0 & 0 & 0 & 9 & 81 \\
\hline Percentage high & 0 & 32 & 0 & 23 & 9 & 0 & 45 & 28 & 23 & 9 & 4.5 \\
\hline Percent no. diff. & $\mathbf{3 2}$ & 63 & $\mathbf{9}$ & $\mathbf{7 2 . 5}$ & 46 & 41 & 55 & 72 & 77 & 82 & 14.5 \\
\hline
\end{tabular}

$L=$ scores significantly below criterion. scores significantly above criterion. 
readers with the application of judgment to situations following some implicit verbal manipulation.

Generally, according to Cohen's factorial analysis, it seems that disabled readers tend to be deficient in those verbal areas requiring the retention of knowledge obtained formally (in school), and in the immediate retention of auditorally-received stimulation. Their strengths seem also to be in verbal comprehension areas, but in the aspect of verbal comprehension requiring the use of practical judgment. Interestingly, there seems to be little, if any distinction between retarded and normal readers on Cohen's Factor B: Perceptual Organization, which involves nonverbal task requiring the interpretation and organization of visuallyperceived materials. Such evidence tends to challenge the credibility of arguments suggesting visual perception difficulties as major components of reading disability.

Aside from the notable findings of a WISC subtest pattern for disabled readers, investigators have frequently noted the visually significant discrepancy between Performance IQ (PIQ) and Verbal IQ (VIQ) scores on the WISC, with PIQ scores usually being higher for retarded readers. While a few studies have found no differences between the VIQ and PIQ scores for their reading disabled groups (Sanstedt, 1964); (Ka11os, et al., 1961); (Silberberg and Feldt, 1968), many seem to report statistically significant differences in these scores (McLean, 1963); (Neville, 1960); (Belmont and Birch, 1966); (Warrington, 1967); (Huelsman, 1970) (Klasen, 1972).

Some investigators have noted that some disabied readers score higher 
on the Performance Scale than on the Verbal Scale, while others score just the opposite (Lyle and Goyen, 1969). They have argued that this disturction may serve to indicate a duoclassification of retarded readers (Klasen, 1972); i.e., two different "types" of reading disability based on different underlying variables. Paterra (1963) studied these two subgroups of retarded readers and found that they did indeed show somewhat different subtest patterns of results. She also noted that those whose VIQ score was significantly greater than their PIQ score showed substantially more subtest variability than the high PIQ-low VIQ group. Reed (1967) determined that school children with high VIQ and low PIQ scores were much less likely to have reading problems. Huelsman (1970) however, argued that while statistically significant differences between VIQ and PIQ scores are often noted, the absolute difference between such scores does not usua11y approach a significant difference appropriate for diagnostic use.

Given these results, research into this potentially fruitful aspect of intelligence test performance, whlle having highly speculative and often contradictory conclusions at this time, should perhaps be expended.

The research concerned with the description of a pattern of subtest results on the WISC has advanced some interesting notions which have, perhaps, increased the understanding of reading disability. It is apparent, however, that such research frequently suffers from the same methodological and conceptual problems mentioned earlier. Especially troublesome is the absence of a consistently accepted operational definition of reading disability. The use of many different measurement 
instruments for reading achievement and the frequent use of different degrees of reading retardation seem to be major problems in the research to date. As before, the result of different research articles cannot be compared. Thus, speculations and hypotheses advanced from the findings cannot be strictly generalized to the entire population of retarded readers.

In addition, there are a number of methodological problems specific to this research which must be considered at this point. First, one must question the usefulness of a profile of subtest results. Statistical procedures which have allowed investigators to report significant group differences tend to obscure individual differences in test performance. As a result, such profiles are of little usefulness to the clinician concerned with individual problems (Kender, 1972) and with the prediction of reading problems (Reed, 1967).

Secondly, the use of different "types" of subjects in these studies, some being from school populations, some from populations of children referred for evaluation to a clinic, and some from actual remedial readIng classes, certainly confuses the issue. It is quite possible that these varied groups are perhaps not realistically homogenous.

Fina1ly, the different types of data collected for analysis have also cast suspicion on the findings. While some studies use deviation scores from the standardized population mean of each subtest, others use deviation scores from individual means. The result may be the collection of two distinct types of data which may not be strictly comparable.

As a result, it can be said that interesting findings have been 
noted which are of theoretical significance for the study of reading disability. However, a cautious approach to the interpretation of such findings, especially with respect to their interpretation in a clinical setting involving the evaluation of a particular child, must be maintained.

Since the careful analysis of intelligence test performance of reading disabled children seems to be a rather fruitful avenue of research, it would perhaps be wise to explore the subtest results of other similar measurement devices. The use of other instruments would, of course, allow for the careful comparison between the test device and the WISC in terms of the deficiencies and proficiencies it found in the intellectual abilities of the reading disabled. It would also perhaps point out some different areas of concern not previously considered. Such a research approach is the focus of the present study.

The McCarthy Scales

A recently developed mental abilities test of seemingly significant potential both for research and for the applied clinician is the McCarthy Scales of Children's Abilities (MSCA) published in 1970 by Dr. Dorothea McCarthy, a noted expert in the fields of child development and child assessment techniques. Kaufman (1973) described her test as follows:

The MSCA is a new, individually administered series of scales which assess the mental and motor abilities of children between the ages of $2 \frac{1}{2}$ and $8 \frac{1}{2}$ years. They provide scores in six distinct areas of mental and motor functioning: Verbal, Perceptual-Performance, Quantitative, General Cognitive, Memory and Motor. 
With the exception of the Motor Scale, which is comprised mostly of non-cognitive tasks, the scales of the MSCA have been found to correlate highly with the Stanford-Binet IQ (.81) and with the three WPPSI IQ scores (.71 for the FSTQ) for a group of 35 six-year-old children (McCarthy, in press) . . suggesting that the General Cognitive Index of the MSCA measures abilities similar to those assessed by conventional intelligence tests.

Since the MSCA is comprised of six separate scales, a brief description of each, provided in the Manual by Dr. McCarthy, would perhaps be of use at this time.

\section{Verbal Scale}

The tests constituting this scale assess the child's ability to express himself verbally and also assess the maturity of his verbal concepts. He is asked to respond with one-word answers, phrases and sentences to a variety of items tapping such mental processes as short- and long-term memory, divergent thinking and deductive reasoning. Five subtests comprise the Verbal Scale.

2. Perceptual -Performance Scale:

This scale, consisting of game-like tasks which do not require the child to speak, assesses his reasoning ability through the manipulation of materials. He demonstrates such skills as imitation, logical classification and visual organization in a variety of spatial, visual-perceptual and conceptual tasks.

3. Quantitative Scale:

This scale measures the child's facility with numbers and his understanding of quantitative words . . . The scale aims to assess the child's number aptitude rather than to explore the upper IImit of his computational skills. Three subtests comprise the Quantitative Scale.

4. General Cognitive Scale:

The General Cognitive Scale is composed of all the tests in the Verbal, Perceptual-Performance 
and Quantitative Scales. Each task is cognitive in nature and the Scale as a whole provides a measure of the child's overall cognitive functioning. The child's General Cognitive Index (GCI) shows his cognitive level in relation to other children of his chronological age. Although the GCI mean of 100 and standard deviation of 16 are essentially the same parameters used to define intelligence quotients obtained from many mental tests, the term IQ has been deliberately avolded because of the many misinterpretations of that concept and the unfortunate connotations that have become associated with it.

\section{Memory Scale:}

Each of the tests in the Memory Scale assesses the child's short-term memory. The assessment of memory in two modalities, requiring both verbal and non-verbal responses and using a variety of stimuli afford extensive evaluation of the child on this very important ability. Four subtests comprise the Memory Scale.

6. Motor Scale:

The tests in the Motor Scale assess the child's co-ordination as he performs a variety of gross and fine motor tasks. A child's Motor Index reflects his developmental level and is a vital adjunct to the picture of the child as revealed by his GCI and his scores in the specific cognitive areas. Five subtests comprise the Motor Scale.

(For a schematic diagram of the overall organization of subtests and Scales of the MSCA, see Table II.)

Since the MSCA is a relatively new test instrument, Ifttle research has been attempted with it to date. However, the few investigations of the MSCA attempted thus far have provided some interesting data both with respect to the structure of the test and with respect to its usefulness as a predictive and diagnostic device. A general review of this 1itera- 
SCALE AND SUBTEST ORGANIZATION OF THE M.S.C.A.

$$
\text { M.S.C.A. Scales }
$$

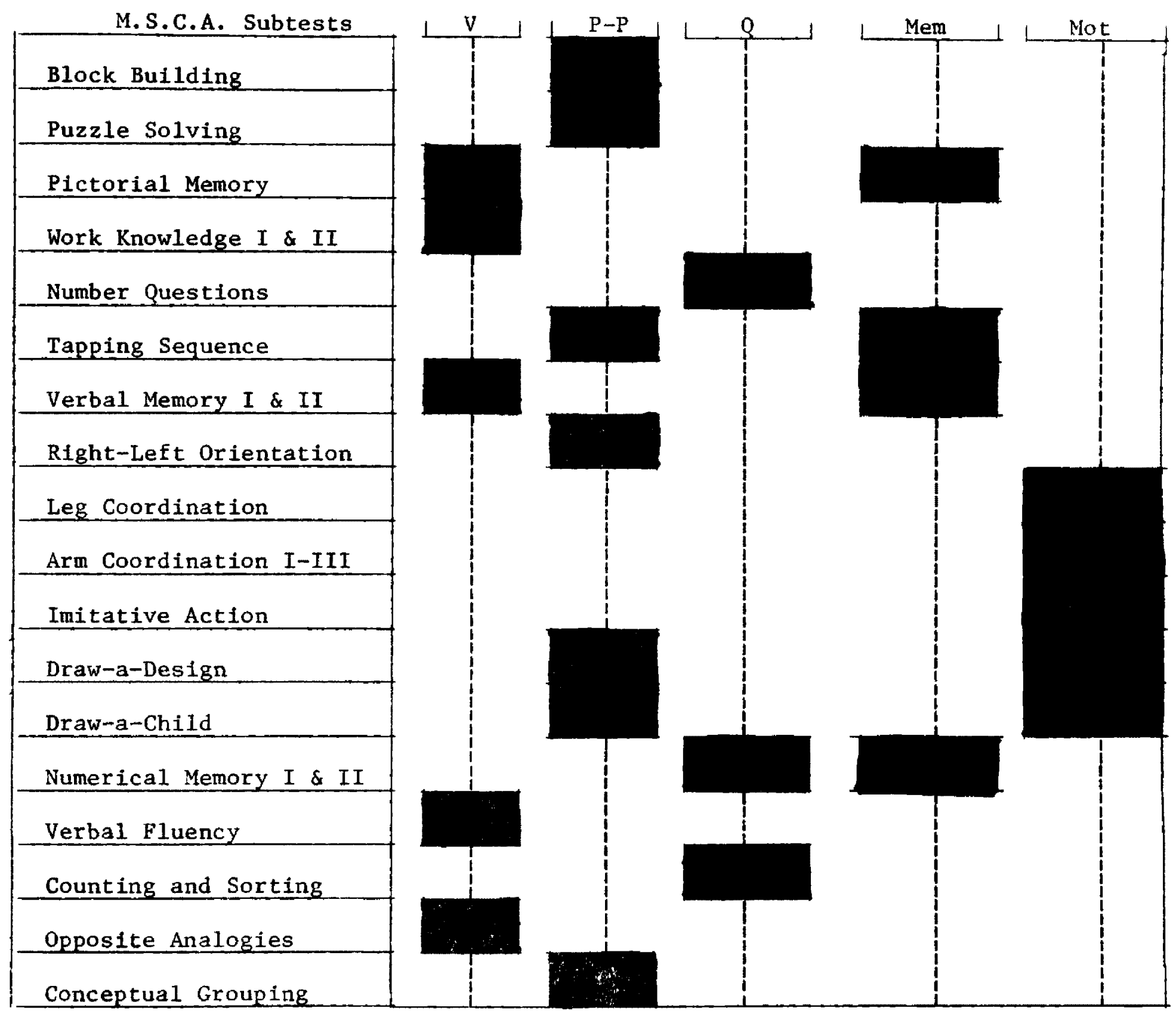

Conceptual Grouping

COMPOSITE RAW SCORE
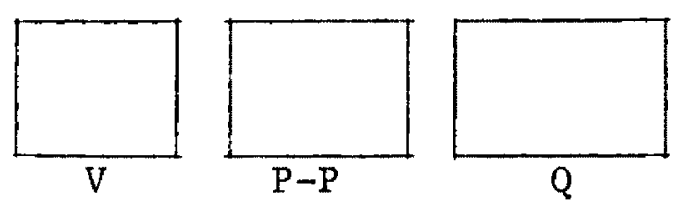

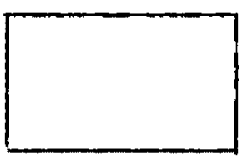

Mets

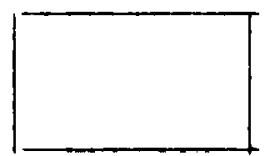

Mot

(NOTE: Each subtest is shaded in line with the scale of which it is a part. Note that some subtests are included in more than one scale.) 
ture is thus necessary at this point.

Two separate studies of the structure of the MSCA have been attempted. The first was a factor analytic study of the MSCA by Kaufman and Hollenback (1972). The authors utilized four separate factor analytic techniques to determine which factors, if any, were consistently isolated with respect to the test performance of 132 five to five-and-a-half-yearold children who constituted $67 \%$ of the standardization sample of children at these two age levels. Their analyses consistently yielded five major factors which they Identified as: (1) General cognitive; (2) Memory/Verbal; (3) Quantitative; (4) Visual memory; and (5) Motor. of the 24 subtests of the MSCA, 15 had meaningful loadings on the general cognitive factor; 7 had meaningful loadings on the memory/verbal factor; 5 had high loadings on the quantitative factor; and 3 had significant loadings on the visual memory and motor factors.

The second study was an attempt to evaluate the consonance of the MSCA with Guilford's (1967) "structure of intellect" model (Kauman, 1973 ). Kaufman attempted to demonstrate the types of abilities measured by the MSCA. In the first dimension of Guilford's three-dimensional model ("operations" or intellectual processes), he found that approximately $50 \%$ of the subtests measured cognitive processes and a nearly equal percentage measured the processes of memory and convergent-production. With respect to the "contents" or types of information to be processed (Guilford's second dimenston), $47 \%$ of the subtests assessed figural contents while $53 \%$ measured semantic content. Only $20 \%$ of the subtests were found to measure symbolic content. For the third dimension of 
Guilford's model ("products" or the organization of information to be processed), $40 \%$ of the subtests assessed "units," $40 \%$ of the subtests assessed "relations," while 53\% measured "systems" and 20\% measured "implications." The author concludes that there is a high degree of consonance between Guilford's model and the structure which McCarthy chose for her Scales. However, while the MSCA does appear to be somewhat consonant with Guilford's model in a descriptive sense, there is no Indication that the MSCA is structurally consonant with Guilford's Structure -of- Intellect model.

In another rather interesting investigation, Kaufman (1973) studied the test results of 35 white, middle-class six-year-olds on the Stanford-Blnet, Wechsler Preschool and Primary Scales of Intelligence (WPPSI), Metropolitan Achievement Tests (MAT) and the MSCA. He found that both the GCI of the MSCA and the Stanford-Binet IQ correlated at .50 with first grade achievement as measured by the MAT. All three tests - the Stanford-Binet, WPPSI, and MSCA - were also correlated significantly with first grade reading achievement as defined by the reading score of the MAT. While the PIQ and VIQ scores of the WPPSI had non-significant correlations with the MAT, the Memory, Perceptual-Performance and Quantitative scores of the MSCA correlated significant1y with the MAT. This would suggest that these scales are efficient predictors of first grade achievement. The GCI, Quantitative and Perceptual-Performance scales of the MSCA also correlated significantly with mathematics and reading achievement scores of the MAT. Thus, it seems that the MSCA can be evaluated as a promising device for the prediction 
of many aspects of first grade achievement.

An interesting study of the relationship of social class to the cognitive and motor abilities of young black children was attempted by Kaufman and Kaufman (1972). They compared the MSCA score of 154 black children of ages two-and-a-half to eight-and-a-half years, of varying socioeconomic classes. Using the father's occupation as an index of socioeconomic status (SES), the authors divided the subjects into two SES groups: a high SES group (professional, technical, managerial, clerical, sales and skilled workers) and a low SES group (semi-skilled and unskilled workers). Their results indicated that the high SES group scored significantly higher on all six scales of the MSCA (p r.01) than the low SES group. Comparing the results of this study to a similar one in progress, the authors concluded that SES is an important variable in MSCA performance and that the variable of SES seems to be more important than the factor of race with respect to MSCA performance.

Finally, in an extremely interesting and significant study of direct relevance to the present study, Kaufman (1972) attempted to evaluate the usefulness of the MSCA in the diagnosis of minimal brain dysfunction (MBD). She hoped to determine which subtests, if any, would distinguish between the test performance of MBD and "normal" children. Forty-four children of ages five to nine, 22 of whom were enrolled in a special class for learning problems resulting from minimal brain dysfunction as diagnosed by school psychologists, were used as subjects. The remaining 22 children were enrolled in regular school classes and exhibited no observable learning problems. The two groups were matched closely 
according to sex, color, age, SES and overall IQ level. Their test results revealed that 12 of the 13 subtests significantly distinguished the groups in favor of the "normals." The most discriminating tests seemed to lie in the Perceptual-Performance and Quantitative scales, although Memory scale tasks involving sequencing were also highly discriminating. The author concludes that the MSCA shows substantial promise as a diagnostic tool for MBD children. However, one wonders, as Huelsman (1970) pointed out, if the determination of group statistical findings of significance necessarily implies diagnostic usefulness in the individual case. More research here must be attempted. Also, further research with respect to other types of learning disabilities should be attempted to see if these results effectively discriminate between types of learning disabilities. Only then will the diagnostic usefulness of the MSCA be adequately determined.

In general, since so little research with the MSCA has been attempted to date, it would be spurious at this time to form conclusions concerning its usefulness either as a mental abilities test or as a diagnostic tool. However, the research which has been attempted has shown that its structure and organization are sound; that it has some predictive validity; and that it perhaps significantly discriminates between certain diagnostic groups and "normal" children. These findings do seem to suggest that the MSCA will quite possibly prove to be an extremely valuable measurement device, and certain1y much more research employing it should be encouraged. 
Research Goals.

In general, the purpose of the present research effort was to determine if significant differences in test performance on the MSCA exist between carefully matched groups of average and below average readers. More specifically, the present research attempted to determine:

a. if significant differences in performance on any of the six MSCA scales could be shown to exist between two matched groups of 25 average and below average readers;

b. if a "profile" of scale scores could be statistically described for each of the reading groups;

c. if a pattern analysis of test performance, involving the assignment of "weights" to each scale scorecould be delineated to maximize scale differences between groups which could also be shown to be of diagnostic use in the individual case.

Since the present research was primarily exploratory in nature, specific hypotheses concerning projected test results for either group were not attempted. However, speculations with respect to the test performance of the below average readers on each of the six MSCA scales were advanced. It should be noted that the speculations advanced here were based primarily on the test results which have been previously discussed for similar groups on the WISC. These speculations, by scales, are as follows:

1. Verbal Scale.

Verbal abilities as measured by the WISC seem to significantly discriminate groups of average and below average readers, However, the subtests of 
the Verbal Scale of the WISC which are most frequently noted as effective discriminators are the Information, Arithmetic and Digit Span subtests, Tests similar in nature to these subtests are not found on the MSCA Verbel Scale however, and thus significant differences between reading groups on this scale were not anticipated.

2. Perceptua1-Performance.

Perceptual abilities as described by the Performance Scale of the WISC have been found to poorly discriminate between average and below average readers. Thus, one would expect that no significant differences between reading groups in their scores on this scale would be found.

3. Quantitative Scale.

The Arithmetic subtest of the WISC, the only major quantitative measure on the test, has been found to be perhaps the most effective discrininator between average and below average readers on that test. Thus, it is likely that the below average readers will score significantly below average on this scale.

4. Memory Scale.

Research seems to indicate, although not conclusively, that poor readers experience difficulty with memory items. Immediate recall abilities and both visual and auditory sequential memory skills seem to be especially troublesome for these children. Thus, one might expect significantly weaker performance by below average readers on this scale.

5. Motor Scale.

Motoric abilities are not specifically measured on the WISC, and thus speculation here seems somewhat more difficult. Since there is little evidence in the literature which suggests that below average readers are also delayed in motor development, there will perhaps be no differences in performance on this scale between reading groups.

6. General Cognitive Scale.

The GCI is composed of scores from the Verbal, Per- 
ceptual-Performance and Quantitative Scales of the MSCA. It has been found to correlate significantly with both the WPPSI and the Stanford-Binet IQ scores. Due to this fact, and due to previous speculations of no differences between reading groups on the Verbal and Perceptual-Performance scales, it seems plausible to suggest that no significant differences between these groups on the GCI score will be found. 


\section{CHAPTER II}

METHOD

\section{Subjects}

Subjects (Ss) used for the present study were selected from the population of second grade male students enrolled in the Lincoln, Bryant, Broadwater and Rossiter Elementary Schools of the Helena School District, Helena, Montana. Teachers of each second-grade class in these schools were requested to point out those children who they suspected to be reading at a grade level equivalent of either 6 months or more below actual grade placement or $0-6$ months above grade placement. The groups of boys selected by the teachers of each school were then administered the otis-Lennon Mental Abilities Test (Elementary $I$ - Form $K$ ) and the Reading subtest of the Metropolitan Achievement Test (Primary II Battery) using standardized administration procedures. Information concerning the child's birthdate and socioeconomic status (occupation of head-of-household) was secured from school records. Only second-grade boys between the ages of 7-0 and 8-1 were considered for the selection of Ss.

From this sample of second-grade boys, only a portion were found to exhibit test characteristics consistent with the demands of the present study. These characteristics, which served as the selection criteria

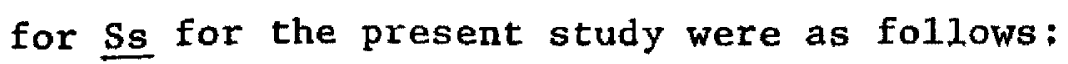

1. Only children receiving $T Q$ scores falling within one standard deviation of the established test norm (84-116 inclusive) of the Otis-Lennon Mental Ability Test were further considered for 
selection.

2. Only children who received a reading achievement score of either:
a.) six months or more below grade level expectation; or
b.) zero to six months above grade level expectation as defined by the Metropolitan Achievement Test (Read- ing subtest) were further considered for selection as Ss for the present study.

3. Only children from homes described as middle SES (ratings 2,3 and 4) by Warner's Revised Scale of Occupational Rating (1949) were further considered for selection.

\section{Procedure}

Forty-eight children (48) were found to meet all of the above selection criteria for the present study. Two (2) separate groups of children were formed on the basis of their reading achievement scores. These two groups were:

1. Group AR - Average Readers

In this group were those boys who scored between zero and six months above grade level expectation as defined by the Reading subtest of the Metropolitan Achievement Test.

2. Group BAR - Below Average Readers

In this group were those boys who scored at least six months below expected grade level achievement as defined by the Reading subtest of the Metropolitan Achievement Test.

On the basis of these criteria, twenty four children were selected as Ss 
for each group. The selection of the Ss was accomplished by an assistant to the author. The author was unaware of the reading scores of any of the Ss so that examiner bias in subsequent testing was not a factor. Group data concerning the average age and IQ levels of each of the groups were tabulated and are presented below in Table III.

Upon the final selection of the two groups of $\underline{\text { s }}$ for the present study, each child was individually administered the MSCA according to standard administration procedures as outlined by McCarthy in the MSCA manual. The author served as the sole examiner for all $\underline{\mathrm{Ss}}$.

\section{TABLE III}

SUBJECT DEMOGRAPHIC DATA

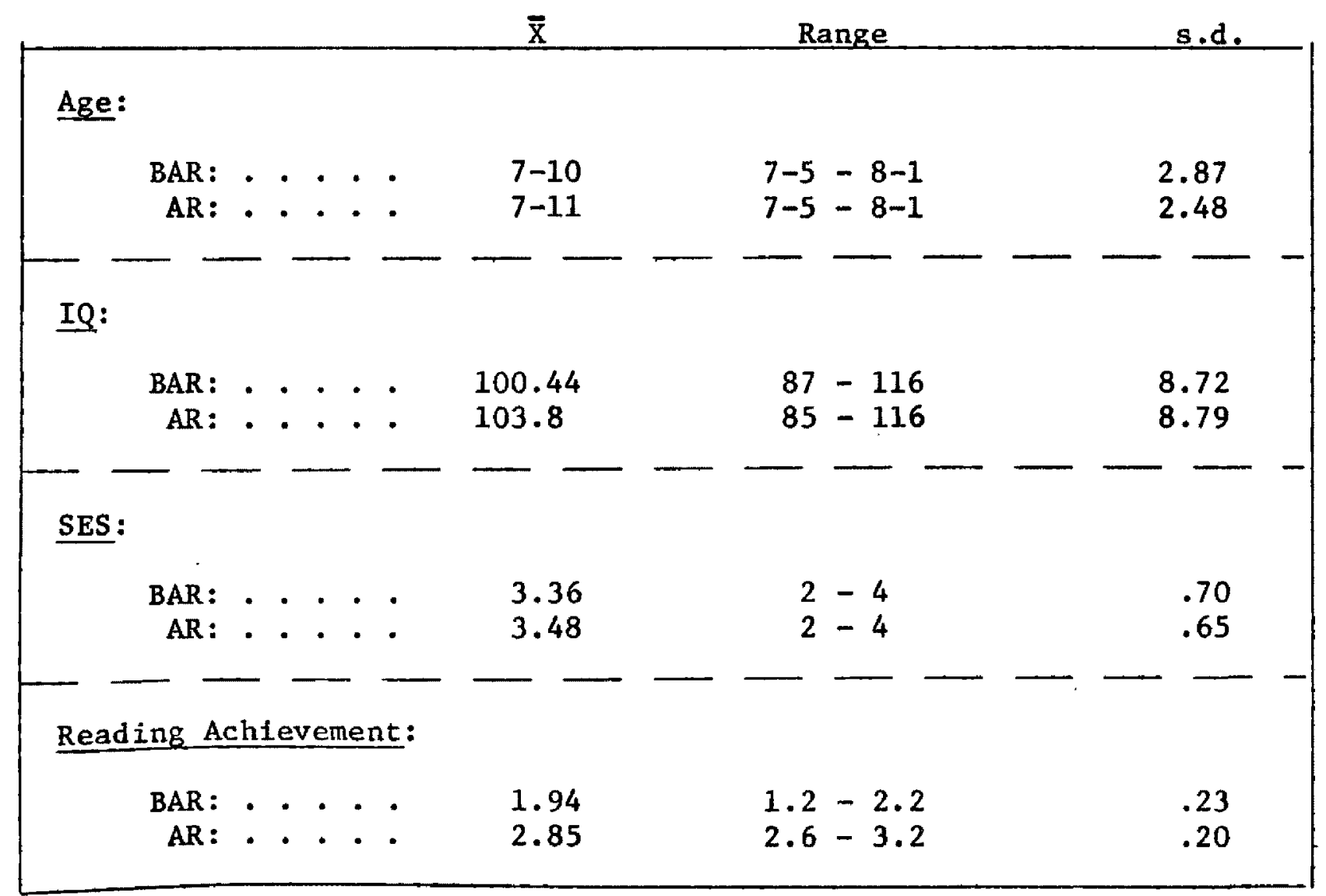




\section{CHAPTER III}

\section{RESULTS}

Upon completion of the testing, each child's performance on the MSCA was scored according to standard scoring procedures as described in the MSCA Manual. Analyses of mean differences in scale index scores between the AR and BAR groups for each of the six MSCA scales was accomplished through the use of Student's $t$ test for two independent samples. The use of non-directional hypotheses required the use of a two-tailed test. The results of the comparisons of the means are presented as follows in Table IV.

TABLE IV

COMPARISON OF MSCA SCALE PERFORMANCE

\begin{tabular}{|c|c|c|c|c|}
\hline Scale & $\overline{\mathrm{x}}$ & $S(x-\bar{x})^{2}$ & $\mathrm{~s}^{2}$ & $t$ \\
\hline \multicolumn{5}{|l|}{ Verbal } \\
\hline $\begin{array}{r}\text { BAR: } \\
\text { AR: }\end{array}$ & $\begin{array}{l}52.6 \\
50.9\end{array}$ & $\begin{array}{l}947.84 \\
959.42\end{array}$ & $\begin{array}{l}41.2 \\
41.7\end{array}$ & 0.895 \\
\hline \multicolumn{5}{|l|}{ Per. - Perf. } \\
\hline BAR: & 51.2 & 1775.36 & 77.19 & 0.372 \\
\hline AR: & 50.2 & 2049.96 & 89.13 & \\
\hline \multicolumn{5}{|l|}{ Quant. } \\
\hline BAR: & 44.4 & 995.64 & 43.29 & 0.406 \\
\hline $\mathrm{AR}$ : & 45.2 & 1061.96 & 46.17 & \\
\hline \multicolumn{5}{|l|}{ GCI } \\
\hline BAR: & 99.2 & 1450.56 & 63.07 & 0.746 \\
\hline AR: & 97.2 & 2357.96 & 102.52 & \\
\hline \multicolumn{5}{|l|}{ MEM. } \\
\hline BAR: & 45.8 & 1617.36 & 70.32 & \\
\hline $\mathrm{AR}:$ & 47.3 & 1266.96 & 55.08 & 0.644 \\
\hline \multicolumn{5}{|l|}{ Motor } \\
\hline BAR: & 53.5 & 2844.00 & 123.65 & \\
\hline AR: & 49.4 & 2521.64 & 109.64 & 1.299 \\
\hline
\end{tabular}


Results of the multiple discriminant function analysis were nonsignificant. The values of the $F$ statistic for the first and all succeeding discriminant functions were less than 1.0 . It was not possible in this situation to find a linear combination of the scales of the MSCA which discriminated between the two reading groups beyond a chance level. Given this fact, plus the nonnsignificant differences between means and variances, none of the necessary conditions for a successful profile analysis existed, and it was therefore not calculated. 
CHAPTER IV

DISCUSSION

An analysis of the results of the present study indicates nonsignificant differences between the test performance of the AR and BAR groups on each of the five MSCA scales and on the General Cognitive Index (GCI). In fact, an examination of Table IV reveals that differences in mean performance between the two groups on a11 MSCA scales were quite small. A number of possible explanations for such unanticipated results will be advanced and discussed in this section.

It seems quite possible that the initial restriction of the IQ range of the $\underline{S s}$ as one aspect of the selection criteria may have influenced the test results. The initial restriction of the IQ range to the 84 - 116 range may have limited the range of variability in test performance on the MSCA. This would, of course, diminish the probability of the expression of group differences on specific scales of the test. However, the restriction of the IQ range to the normal range of functioning has not appeared to create a similar effect with respect to the test performance of similar groups of the WISC. In a number of studies (Kallos, Grabow \& Guarino, 1961); (Sawyer, 1965); (Reid \& Schoer, 1966), the restriction of IQ range had little effect on the pattern of WISC subtest performance in comparison to those studies which did not initially restrict the IQ range. It is possible, however, that the MSCA is more sensitive to such restrictions than the WISC. Such a notion is, of course, merely conjectural and requires empirical verification. 
Another plausible explanation for the present results may involve the age level of the SS of the study. Mean ages for the BAR and AR groups were, respectively, 7-10 and 7-11. The upper age limit of the MSCA is only a few months above, at 8-6. Due to the advanced age of the $\underline{S}$ there were a number of subtests on which a majority of the $\underline{S s}$ of both groups achieved a maximun possible score. On these subtests - Block Building, Word Knowledge I, Imitative Action, Counting and Sorting, Conceptual Grouping - the mean performance of both groups closely approximated the maximum allowable score. Table $\mathrm{V}$ below provides a summary of the $\underline{S s}^{\prime}$ performance, by group, on these five subtests.

\section{TABLE V}

GROUP PERFORMANCE ON 5 SELECTED MSCA SUBTESTS

\begin{tabular}{|c|c|c|c|} 
Subtest Mean Score & $\begin{array}{c}\text { Percentage Having } \\
\text { Maximum Score }\end{array}$ \\
\hline Block Building & & & \\
AR: & 10 & 9.92 & $92 \%$ \\
BAR: & 10 & 9.95 & $96 \%$ \\
\hline Word Knowledge I & & & $100 \%$ \\
\hline AR: & 9 & 9 & $100 \%$ \\
\hline BAR: & 9 & 9 & \\
\hline Imitative Action & & & $83 \%$ \\
\hline AR: & 4 & 3.83 & $87.5 \%$ \\
BAR: & 4 & 3.87 & $79 \%$ \\
\hline Counting \& Sorting & & & $75 \%$ \\
\hline AR: & 9 & 8.75 & $8 \%$ \\
BAR: & 9 & 8.75 & $17 \%$ \\
\hline Conceptual Grouping & & & 10.0 \\
\hline AR: & 12 & 10.22 & \\
\hline BAR: & 12 & & \\
\hline
\end{tabular}


Thus, it seems that the variability in performance on these subtests may

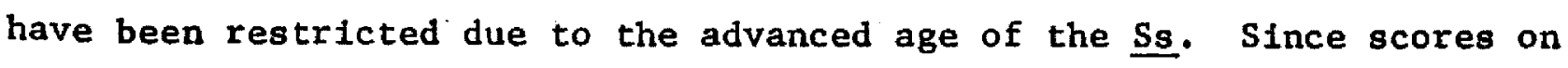
these subtests were not free to vary at the upper levels, possible group differences in performance on these subtests may have been precluded. Another major, and perhaps quite significant methodological consideration which may have influenced test results involves the degree of reading retardation for the BAR group. In the present study, a discrepancy of six months or more between expected grade level reading achievement and actual reading achievement as defined by the Reading subtest of the Metropolitan Achievement Test served as the sole criterion for placement in the BAR group. While such a discrepancy at the secondgrade level would seem significant, it may have been too subtle a discrepancy between groups to have been measurable by the MSCA. It is interesting to note that most similar studies utilizing the WISC, especially those which also restricted the IQ range of $\underline{S s}$ as mentioned previously, have used degrees of reading retardation which are substantially greater than the degree used for the present study. Certainly a replication of the present study utilizing an increase in the degree of reading retardation for the BAR group would provide a useful and interesting examination of this notion.

In general, it seems plausible to speculate that three of the methodological aspects of the present study - the restriction of the IQ range, the advanced age of the $\underline{S} s$, and the limited degree of reading retardation for the BAR group n may have contributed substantially to the present results. of course, all three tentative explanations remain 
quite speculative at this time, requiring empirical verification. Hopefully, further research into these areas will be attempted in the near future.

The possibility of the influence of methodological considerations notwithstanding, it seems as though alternative explanations of the present results are also plausible. It is certainly plausible to suggest that the present results are in fact providing relevant information concerning the nature of intellectual strengths and weaknesses of the disabled reader as defined by the MSCA. Thus, a brief discussion of the resuits of test performance, by scale, seems quite relevant at this point.

On the Verbal Scale of the MSCA, non-significant differences between the mean scores of the two reading groups were noted. On the surface, this would seem to be contrary to the findings of a majority of studies involving the Verbal Scale of the WISC (Klasen, 1972). However, it seems as though the Verbal Scale of the MSCA may be measuring different aspects of verbal functioning than does the WISC. Aspects of verbal functioning such as those measured by the Vocabulary and Similarities subtests of the WISC seem also to be measured by the Verbal Scale of the MSCA. On these WISC subtests, the majority of studies previously reviewed found no significant differences between reading groups. Those WISC subtests which seemed to depress the Verbal Scale scores of the retarded readers were the Information, Arithmetic and Digit Span subtests. It seems that on the MSCA Verbal Scale, subtests comparable to these are not included. Rather, verbal skills such as pictorial memory, verbal 
memory and verbal fluency seem to be included. It seems that these differences in the types of verbal abilities assessed by each test may lead to quite different test results. In short, those verbal abilities which seem to most effectively distinguish between reading groups on the WISC are not included on the Verbal Scale of the MSCA. On the other hand, those verbal skills which do not tend to distinguish between reading groups on the WISC Verbal Scale are also included on the verbal scale of the MSCA. For these reasons it is perhaps not surprising that non-significant mean differences between the AR and BAR groups were noted. Findings such as these may also be seen as somewhat supportive of the earlier notions advanced by Hirst (1960) and Robeck (1964), who suggest that those verbal abilities which seem to be acquired through the application of intellectual activity to environmental situations do not seem to be particularly deficient in the retarded reader.

On the Perceptual-Performance Scale of the MSCA, significant differences in scores between the AR and BAR groups were not found. Research findings concerning the Performance Scale of the WISC indicate little difference in test results between average and poor readers on this scale (Klasen, 1972). Measures of perceptual organization (primarily visual organization) seem to comprise most of the subtests of the Performance Scale of the WISC (Cohen, 1959). Similarly, McCarthy suggests that her Perceptual-Performance Scale also primarily measures visual organization. Thus, it is not surprising that scores representing this aspect of intellectual functioning did not effectively discriminate between the AR and BAR groups. This finding tends to support previously 
discussed notions that visual perception deficiencies are not a major characterlotic of the reading disabled (Golden \& Stelner, 1967) (Liebert \& Sherk, 1970) (Hartlage, 1970) (01son \& Johnson, 1970).

The Quantitative Scale of the MSCA has little direct comparison to either the Verbal or Performance Scales of the WISC. In fact, the only direct measure of quantitative ability on the WISC seems to be the Arithmetic subtest of the Verbal Scale. Interestingly, the Arithmetic subtest seems to be the most effectively discriminating subtest between average and poor readers on the WISC. Thus, it is somewhat surprising that the MSCA Quantitative Scale did not significantly discriminate between the AR and BAR groups. However, the Quantitative Scale of the MSCA comprises a series of four subtests which assess not only computational sk111s (Number Questions) but also numerical aptitude (Counting and Sorting) and numerical memory. It does seem possible that while the disabled readers may be deficient in computational ability, they may not be particularly deficient with respect to numerical aptitude or memory. If this were the case, then one would perhaps not expect the Quantitative Scale scores of the BAR group to be especially lower than the same scores of the AR group. One has to question this hypothesis, however, since a mean comparison of the scores of the two groups on the Number Questions subtest was also non-significant $(t=.51, p>.05)$. Since the Arithmetic subtest of the WISC and the Number Questions subtest of the MSCA seem to be quite similar tests, one is Inclined to resort to the possible effects of the methodological considerations mentioned pre- 
viously as an explanation for the present results. Perhaps the correlation between computational deficiencies and reading disabllity becomes significant only with a more severe degree of reading difficulty than was utilized in the present study. Such a notion is, of course, merely speculative at this time. Further research investigation into this matter is required, and might prove to be quite interesting.

On the Memory Scale of the MSCA, mean differences in scale index scores between the AR and BAR groups were also found to be non-significant. Given the attention in the 1iterature to the possibility of deficient memory abilities in the disabled reader.(Tjossem, 1963) (Guthrie \& Goldberg, 1972) (Cline and Lee, 1971), such results are perhaps somewhat surprising. However, the Memory Scale of the MSCA represents a much more extensive evaluation of short-term memory abilities than is found on the WISC. McCarthy suggests that her Memory Scale measures sequential memory involving both the auditory and visual channels simultaneously and also auditory sequential memory solely. Thus, given the results of the present study, one would be inclined to discredit notions of a noticeable short-term memory deficiency in disabled readers. However, as discussed above, methodological considerations of the present study described earlier may be influencing the results of the Memory Scale. Here too, further research investigation is required. Finally, group results of the mean comparison of scale index scores on the Motor Scale of the MSCA were also noted as non-significant. Such a result does not seen particularly surprising however, since very little emphasis in the literature to date has focused on the motor abilities 
of disabled readers. Perhaps the most compelling explanation for these results is supplied by McCarthy herself in the Manual (p. 6) where she suggests that for older chlldren (above age six), the tasks of the Motor Scale may be rather easy for the child and thus may not challenge or effectively assess his gross and fine motor abilities. Whether or not this is the case, it does seem fairly clear on the basis of the results of the present study and of the review of the relevant 1iterature that gross and fine motor abilities do not appear to be significantly correlated with the phenomenon of reading disability.

Aside from the discussion of the results of the present study with respect to scale index scores, it is also perhaps interesting to note the group data concerning the observations on laterality of the present study. In the AR group, fully $71 \%$ of the Ss did not exhibit an established eye-hand dominance. Thirty-three per cent of these Ss exhibited mixed eye-hand dominance while $37.5 \%$ of these Ss were observed to have not clearly established hand preference.

For the BAR group, $62.5 \%$ of the Ss failed to exhibit an established eye-hand dominance. In this group, $29 \%$ were observed to exhibit mixed eye-hand dominance while $33 \%$ did not exhibit a clearly established hand preference.

It should perhaps also be noted that on the R - L Orientation subtest of the MSCA, which McCarthy suggests is a measure of directional or spatial orlentation, mean performance of the two groups did not differ significantly. In general, given these observations on laterality from the test situation, one would be inclined to suggest that these various 
aspects of lateral confusion do not seem to be especially characteristic of the reading disabled.

Overall conclusions concerning the results of the present study seem, at this point, rather difficult to assess. Since mean comparisons of the test performance of the two groups revealed non-significant differences on al1 of the MSCA Scales, one is tempted to assert that the MSCA may not prove to be an especially useful test instrument in the diagnosis of reading disability or in the description of possible intellectual deficiencies of disabled readers. However, it is important to realize that certain methodological considerations of the present study, mentioned previously, may be significantly influencing the dimension of test results. Further research is thus necessary to resolve this important issue. Until further research is accomplished, it seems necessary to suggest that judgment concerning the usefulness of the MSCA with respect to the reading disabled be suspended. 


\section{CHAPTER V}

\section{SUMMARY}

The present study was an attempt to compare the test results of matched groups of average and below average readers on the McCarthy Scales of Children's Abilities (MSCA). The MSCA is a newly developed measurement device of general cognitive abilities for children between the ages of $2 \frac{1}{2}$ and $8 \frac{1}{2}$ years. It has been suggested that the MSCA might have considerable diagnostic usefulness regarding children with learning and behavioral difficulties.

For the present study, two groups of second-grade male readers were selected as $\underline{S}$. AlI students were initially administered the Otis-Lennon Mental Abilities Test (OLMAT) and the Reading subtest of the Metropolitan Achievement Test (MAT). Each $\underline{S^{\prime} s}$ age was determined and a rating of their socioeconomic background (occupation of head-of-household) was attempted. Only those students whose OLMAT score was within one standard deviation of the test norm (84-116); whose socioeconomic rating was in the middle range as defined by Warner's Revised Scale of Occupational Rating and whose age was between 7-0 and 8-1 were considered for selection as $\underline{\text { ss. }}$ Average readers (AR) were defined as those children whose MAT Reading Scores were between 0 and 6 months above grade level expectancy as defined by the test. Below average readers (BAR) were defined as those children whose reading scores were at least 6 months below expected grade level. 
On the basis of these selection criteria, two groups of $\underline{\text { Ss were }}$ formed ( $N=24$ in each group). Each $\underline{S}$ was then administered the MSCA and the test results for each group were compared. Mean comparisons of scale index scores between the two groups yielded non-significant differences on al1 six MSCA scales. These results were discussed with an emphasis on three methodological factors which may have influenced the test results. These factors included the initial restriction of IQ range, the advanced age of the $\underline{S s}$ with respect to the age limits of the test, and the use of a rather limited degree of reading retardation for the BAR group. A replication of the present study, with an improvement in these methodological factors, was strongly recommended. It was also suggested that until further research can be attempted, judgment concerning the diagnostic usefulness of the MSCA for the problem reader be suspended. 


\section{REFERENCES}

Altus, G.T. A WISC profile for retarded readers. Journal of Consulting Psychology, 1956, 20, 155-156.

Applebee, A.N. Research in reading retardation: Two critical problems. Journal of Child Psychology and Psychiatry, 1971, 12, 91-113.

Belmont, L. \& Birch, H.G. The intellectual profile of retarded readers. Perceptual and Motor Skills, 1966, 22, 787-816.

Bender, Lauretta. Psychopathology of Children with Organic Brain Disorders. Springfield, Illinois: Charles C. Thomas. 1956.

Bentzen, F. Sex ratios in learning and behavior disorders. American Journal of Orthopsychiatry, $1963,33,92-98$.

Bryan, Q.R. The relative importance of intelligence and visual perception in predicting reading achievement. California Journal of Educational Research, $1964,15,44-48$.

Burks, H.F. \& Bruce, P. The characteristics of poor and good readers as disclosed by the Wechsler Intelligence Scale for Children. Journal of Educational Psychology, 1955, 46, 488-493.

Chandler, T.A. Reading disability and socioeconomic status. Journal of Reading, $1966,5-21$.

Clarke, M.M. Symposium on reading disability. British Journal of Educational Psychology, 1971, 41, 14-18.

Cline, C.L. \& Lee, N. A transcultural study of dyslexia: Analysis of language disabilities in 277 Chinese children simultaneously learning to read and write in English and Chinese. Journal of Special Education, 1972, 6(1), 9-26.

Cohen, J. The factorial structure of the WISC at ages 7-6, 10-6 and 13-6. Journal of Consulting Psychology, 1959, $23(4), 585-599$.

Corwin, B.J. The relationship between reading achievement and performance on individual ability tests. Journal of Schoo1 Psychology, 1967 , 5,186 .

DeBruler, R.M. An investigation of relationships between subtest scores on the WISC and reading ability. Dissertation Abstracts, 1968 , $29(1-A), 143-144$. 
Dockre11, W.B. The use of the WISC in the diagnosts of retarded readers. Alberta Journal of Educational Research, 1960, 6, 86-91.

Ekwa11, E.E. The use of WISC subtest profiles in the diagnosis of reading difficulties. Dissertation Abstracts, 1967, 27(4-A), 950-951.

Evans, J.R. Auditory and auditory-visual integration ski1ls as they relate to reading. Reading Teacher, 1969, 22, 625-629.

Fernald, G.M. Remedial Techniques in Basic School Subjects. New York: McGraw-Hil1, 1943.

Gates, A.I. Sex differences in reading ability. Elementary School Journal, $1961,61,431-434$.

Gates, A.J. The Improvement of Reading. New York: MacMillan \& Company, 1947.

Golden, N.E. \& Steiner, S.R. Auditory and visual functions in good and poor readers. Journal of Learning Disabilities, 1969, 2 , 476-481.

Graham, E.E. Wechsler-Bellevue and WISC scattergrams of unsuccessful readers. Journal of Consulting Psychology, 1952, 16, 268-271.

Guthrie, G.T. \& Goldberg, H.K. Visual sequential memory in reading disability. Journal of Learning Disabilities, 1972, 5, 41-46.

Hartlage, L.C. Differential diagnosis of dyslexia, minimal brain dysfunction, and emotional disturbances in children. Psychology in the schools, $1970,7,403-406$.

Herman, Knud. Reading Disability. Springfield, Illinois: Charles C. Thomas, 1959.

Hirst, L.S. The usefulness of a two-way analysis of WISC subtests in the diagnosis of remedial reading problems. Journal of Experimental Education, $1960,29,153-160$.

Huelsman, C.B. The WISC subtest syndrome for retarded readers. Perceptual Motor Skills, 1970, 30, 535-550.

Jeffares, D.J. \& Cosens, G.V. Effect of SES and auditory discrimination training on first-grade reading achievement and auditory discrimination. Alberta Journal of Educational Research, 1970, $26(3), 165-178$.

Kallos, G.L. \& Grabow, J.M. \& Guarino, E.A. The WISC profile of disabled readers. Personnel and Guidance Journal, 1961, 39, 276-278.

Kaufman, A.S. Analysis of the McCarthy Scales in terms of Guilford's structure of intellect mode1. Perceptual Motor Ski1ls, 1973, $36,967-976$. 
Kaufman, A.S. Comparison of the WPPSI, Stanford-Binet and McCarthy Scales as predictors of first-grade achievement. Perceptual Motor Skilis, $1973,36,67-73$.

Kaufman, N. Evaluation of the MSCA for use with children having minimal brain dysfunction. Proceedings of the 8 th Annual Convention of the APA, 1972.

Kaufman, A. Kaufman, N. The relationship of social class to the cognitive and motor abilities of young Black children. Unpublished doctoral dissertation, Columbia University, 1972.

Kauman, A.S. \& Hollenbeck, G.P. Factor analysis of the MSCA at age five. Paper presentation, EPA Convention, Boston, Massachusetts. Apri1, 1972.

Kender, J.P . Is there really a WISC profile for retarded readers? Journal of Learning Disabilities, $1972,5,397-400$.

Kephart, N.C. The Slow Learner in the Classroom. Columbus, Ohio: Charles E. Merrill Books, Inc. 1960.

Klasen, Edith. The Syndrome of Specific Dyslexia. Baltimore, Maryland: University Park Press, 1972.

Kolson, C.J. \& Kaluger, G. Reading and Learning Disabilities. Columbus, Ohio: Charles E. Merrill Publishing Company, 1969.

Langman, M.P. The reading process: a descriptive, interdisciplinary approach. Genetic Psychology Monograph, 1960, 62, 3-40.

Larsen, S, Performance of achieving and underachieving second, third, and fourth grade children on tests of auditory ability and oral form discrimination. Kansas Studies in Education, 1971, 21(2), 53-59.

Leibert, R.E. \& Sherk, J.K. Three Frostig visual perception subtests and specific reading tasks for kindergarten, first and second grade children. Reading Teacher, 1970, 24, 130-139.

Linder, R: \& Fillmer, H.T. Auditory and visual performance of slow readers. Reading Teacher, $1970,24,17-22$.

Lyle, J.G. \& Goyen, J. Performance of retarded readers on the WISC and educational tests. Journal of Abnormal Psychology, 1969, $74(1), 105-112$.

Mahalanobis, P.A. On the generalized distance in statistics. Proceedings of the National Institute of Science and Industry, $1936,12,49-55$. 
Mazurkiewicz, A.J. Sociomcultural influences and reading. Journal of Developmental Reading, 1960, 3, 254-263.

McCarthy, D. The McCarthy Scales of Children's Abilities. New York: Paychological Corporation, 1970.

McLean, T.K. A comparison of the subtest performance of two groups of retarded readers with like groups of non-retarded readers on the WISC. Unpublished doctoral dissertation, 1963 (University of Oregon).

McLeod, J. A comparison of WISC subtest scores of pre-adolescent successful and unsuccessful readers. Australian Journal of Psychology, $1965,17,220-228$.

Myklebust, Helmer. Learning disorders, psychoneurological disorders in childhood. Rehabilitation Literature, 1964, 25(12), 354-360.

Neville, D. A comparison of the WISC pattersn of male retarded and nonretarded readers. Journal of Educational Research, 1961, 54 , 194-197.

Nunnally, J.C. Psychometric Theory. New York: McGraw-Hill, Inc., 1967.

0lson, A.V. \& Johnson, C.I. Structure and predictive validity of the Frostig Developmental Test of Visual Perception in grades 1 and 3 . Journal of Special Education, 1970, $4(1), 40-52$.

Orton, S.T. Reading, Writing and Speech Problems in Children. New York: W.W. Norton \& Company. 1937.

Paterra, M.E. A study of 33 WISC scattergrams of retarded readers. Elementary English, 1963, 40, 394-407.

Reed, J.C. Reading achievement as related to differences between WISC Verbal and Performance IQs. Child Development, 1967, 38(2), 835-840.

Reed, J.C. The deficits of retarded readers: fact or artifact? Reading Teacher, 1970, 23, 347-352.

Reid, W.R. \& Schoer, J. Reading achievement, social class and subtest pattern on the WISC. Journal of Educational Research, 1966, $59(10), 469-472$.

Reilly, D.H. Auditory-visual integration, sex and reading achievement. Journal of Educational Psychology, 1971, 62, 482-486.

Robeck, M.C. Subtest patterning of problem readers on the WISC. California Journal of Educational Research, 1960, 11, 110-115. 
Robeck, M.C. Intellectual strengths and weaknesses shown by reading clinic subjects on the WISC. Journal of Developmental Reading, $1964,7,120-129$.

Robinson, H.M. Why Pupils Fail in Reading. Chicago: University of Chicago Press. 1946.

Sawyer, R.I. Does the WISC discriminate between mildly disabled and severely disabled readers? Elementary School Journal, 1965, $66,97-106$.

Sheldon, M.S. \& Garton, J. A note on "a WISC profile for retarded readers." Alberta Journal of Educational Research, 1959, 5, 264-267.

Silberberg, N. \& Feldt, L.S. Intellectual and perceptual correlates of reading disabilities. Journal of School Psychology, 1968, $6(4), 237-245$.

Sinks, N.B. \& Powell, M. Sex and intelligence as factors in achievement in reading in grades 4-8. Journal of Genetic Psychology, $1965,106,67-79$.

Strauss, A.A. \& Lehtinen, L.E. Psychopathology and Education of the Brain-injured Child. New York: Grune \& Stratton, 1947.

Tjossem, T.D. \& Hansen, T.J. \& Ripley, H.S. An investigation of reading difficulty in young children. American Journal of Psychiatry, 1962, 118, 1104-1113.

Thompson, L.J. Reading Disability: Developmental Dyslexia. Springfield, Illinois: C.C. Thomas, Publishing Company, 1966.

Warrington, E.K. The incidence of verbal disability with retardation reading. Neuropsychologia, $1967,5,175-179$.

Weintraub, S. Sex differences in reading achievement. The Reading Teacher, 1966, 20, 155-165.

Wozencraft, $M$. A comparison of the reading abilities of boys and girls at two grade levels. Journal of the Reading Specialist, 1967, 6, 136-139.

Zeman, S.S. A summary of research concerning laterality and reading. Journal of the Reading Specialist, 1967, 116-123. 